\title{
Why so many flowers? A preliminary assessment of mixed pollination strategy enhancing sexual reproduction of the invasive Acacia longifolia in Portugal
}

\author{
Manuela Giovanetti, Margarida Ramos, and Cristina Máguas \\ Center for Ecology, Evolution and Environmental Changes (cE3c), Faculdade de Ciências \\ da Universidade de Lisboa, Lisbon, 1749-016, Portugal
}

Correspondence: Manuela Giovanetti (manuela.giovanetti@gmail.com)

Received: 28 September 2017 - Revised: 3 February 2018 - Accepted: 22 February 2018 - Published: 28 March 2018

\begin{abstract}
Acacia longifolia, a native legume from Australia, has been introduced in many European countries and elsewhere, thus becoming one of the most important global invasive species. In Europe, its flowering occurs in a period unsuitable for insect activity: nonetheless it is considered entomophilous. Floral traits of this species are puzzling: brightly coloured and scented as liked by insects, but with abundant staminate small-sized flowers and relatively small pollen grains, as it is common in anemophilous species. Invasion processes are especially favoured when reshaping local ecological networks, thus the interest in understanding pollination syndromes associated with invasive plant species that may facilitate invasiveness. Moreover, a striking difference exists between its massive flowering and relatively poor seed set. We introduced a novel approach: first, we consider the possibility that a part of the pollination success is carried on by wind and, second, we weighted the ethological perspective of the main pollinator. During the flowering season of A. longifolia (February-April 2016), we carried on exclusion experiments to detect the relative contribution of insects and wind. While the exclusion experiments corroborated the need for pollen vectors, we actually recorded a low abundance of insects. The honeybee, known pollinator of acacias, was relatively rare and not always productive in terms of successful visits. While wind contributed to seed set, focal observations confirmed that honeybees transfer pollen when visiting both the inflorescences to collect pollen and the extrafloral nectaries to collect nectar. The mixed pollination strategy of A. longifolia may then be the basis of its success in invading Portugal's windy coasts.
\end{abstract}

\section{Introduction}

Pollination and seed set are crucial aspects of any plant species. Flower traits evolved in different directions, following pollen dispersion by wind or animals (Faegri and Van der Pijl, 1979; Culley et al., 2002). Angiosperms differentiated flowers, e.g. the costly features, along the two most common vectors: bees, among biotic vectors, and wind, among abiotic. When the vectors are bees, flowers are complex structures since they have to counterbalance visitor needs, the heterogeneity of handling strategies and discriminating abilities, with a special focus on attractiveness. Flowers show colourful corollas, provide a landing surface, and are scented (Proctor et al., 1996). The pollen is produced in relatively low quantities, and it is often associated with an- other resource, the nectar. Instead, when the vector is wind, colours and scents are not needed, and the overall structure of the flower is reduced by avoiding a conspicuous corolla. Flowers are often small and abundant, with numerous stamens yielding large quantities of pollen with nectar not being produced (Ackerman, 2000). It is generally expected that anemophilous flowers are as a result unattractive to bees. Yet, pollen abundance turns them into unforeseen showy displays, incidentally attracting the bees when flowering occurs in coincidence with their foraging activity (Aronne et al., 2012). Pollen is a compelling resource for bees, and they can count on plasticity of behaviours to overcome handling inconvenience of anemophilous flowers (Giovanetti and Aronne, 2011). This may translate into misinterpretations after recording bee presence on flowers. There 
is still no consensus: are bees contributing to the pollination of (some) anemophilous species? On the opposite side, to what extent may wind be implied in the pollination of (entomophilous) ones? Too many variables and evolutionary paths are involved in pollination strategies to be successful in designing a solid expectation for seed set, even based on a single pollination scenario taken into account. There are some good reviews to acknowledge that clarify the complexity of the topic and the difficulty in developing sound theoretical background, either using simulation models or more classical approaches. Friedman and Barrett (2009) pointed out the lack of studies on the reproductive characteristics of wind pollinated species (e.g. frequency of pollen limitation, investment in male vs. female flowers, pollen transfer efficiency) that may help in understanding and predicting the evolution of anemophily. Another sound review is that of Goulson (1999), who pointed out the many variables related to the foraging strategies of insects gathering pollen and nectar (source search and distribution patterns, discrimination among individual flowers, competition, decision making processes) directly involved in plant ecology and evolution. More recently, Del-Claro et al. (2013) underlined the urgency of addressing plant-animal interactions from a wider perspective, including aspects of life histories, biology and behaviour besides trophic relationships. Possibly a neglected aspect of pollination issues is the concept of ambophily. As we gather more information on the aspects of co-occurring animal and wind pollination, the more we may understand of the transition from one strategy to the other and the expected outcomes in terms of seed set.

The reproductive success of a plant species relies on the pollination mode adopted, and the success is even more striking when it is about IAS (invasive alien species). IAS have expanded rapidly in the last 100 years. Their expansion brought about extensive effects on biodiversity, ecosystem services, soil composition, wildfire regimes, yield losses, and even public health issues. Among IAS, acacias show outstanding abilities, they can alter water balance and carbon gain of native species (Rascher et al., 2011a), vegetation structure and regeneration on dunes (Rascher et al., 2011b; Del Vecchio, 2013), as well as alter soil, bacterial, fungal and plant communities (Lazzaro et al., 2014). Australian acacias have been intentionally introduced for reforestation or horticultural purposes (Richardson et al., 2011). On Portuguese coastal dunes, Acacia longifolia (Andrews) Willd. is one such introduced species (Castroviejo et al., 1998 and Breton et al., 2008). Negative impacts have been recorded on native biodiversity (e.g. Hellmann et al., 2011; Marchante et al., 2003), ecosystem functioning and community structure (Rascher et al., 2011a, 2012; Ulm et al., 2017). Even if literature exists on acacia flower characteristics and their reproductive conditions (reviewed by Stone et al., 2003, and by Kenrick, 2003), pollination and seed set are still poorly known for many species, especially in invaded areas.
Acacias have always been considered to address only biotic pollination. Acacia inflorescences can be spotted from a distance due to their bright yellow colour and they also have a delicate scent. Some species (e.g. A. longifolia and A. pycnantha) are known to produce nectar, although on EFN (extrafloral nectaries), during the flowering season (Thorp and Sugden, 1990). Nectar produced by A. pycnantha was highly attractive to foraging honeybees in an invasion area in Italy (Giovanetti et al., 2015). Based on these features, it was long assumed that Acacia pollination is due to insects (Tybirk, 1997). In Australia, previous studies showed that Hymenoptera were the most important taxa, compared with other insect groups (Knox et al., 1985; Bernhardt et al., 1984). Bernhardt (1987) found A. mellifera to be the most abundant foraging bee on A. longifolia in the plant's home range, where A. mellifera is, nonetheless, introduced. Behavioural observations, as suggested by Del-Claro et al. (2013), may give important insight into co-evolutionary mechanisms. That was the case for data on honeybee time of pollen and nectar collection on the invasive A. pycnantha. Bee activity perfectly matched the time of resource release, occurring at a different time of the day and, for nectar, also physically distant from the flowers. This happened notwithstanding the lack of a long-term co-evolution in time and space between the alien plant and the native pollinator (Giovanetti et al., 2015). The problem for sexual pollination of acacias in invaded areas is that the majority of species bloom at the very end of the winter, when weather conditions are still prohibitive for insect activity. Therefore, matching bee pollination may be reduced to few mild and warm days. How is it then possible that acacias are so successful?

Anemophily advocates for an abundant number of staminate small-sized flowers, lacking a fully developed corolla and grouped into an inflorescence (Faegri and Van der Pijl, 1979; Proctor et al., 1996). In addition, pollen grains are small in diameter here relative to biotically pollinated plants (i.e. $20-60 \mu \mathrm{m}$ vs. $<200 \mu \mathrm{m}$; Ackerman, 2000). Acacias match the above characteristics defined for anemophilous species. They form dense inflorescences and show numerous flowers per flower head, abundant stamens per flower, and functionally male flowers (Correia et al., 2014; Giuliani et al., 2016). Pollen diameter is $30-70 \mu \mathrm{m}$ in most Australian acacias (Guinet, 1981), and even if rarely taken into account, acacia pollen was recorded in aerobiological surveys of South America, Jordan, and Italy (Sanchez-Medina and Fernandez, 1966; Al-Eisawi and Dajani, 1988; Romano, 1988; Hurtado and Alson, 1996) confirming that wind is able to conveniently handle the polyad (composite pollen grains). Moreover, some environmental conditions are supposed to favour anemophily, such as low species diversity and higher proportions of conspecifics (Ackerman, 2000). In fact, this is what we observe in invaded areas, where acacias form dense aggregations of a single or few species (Marchante et al., 2003). Wind may then be the alternative strategy helping acacia reproduction in invaded areas. 
Acacia is a genus with an outstanding number of species: 1064 combining Asian, Australian, and Pacific data (http://worldwidewattle.com/infogallery/species/; verified on 24 June 2017). Since Acacia species are usually self-infertile, we planned exclusion experiments to verify the relative contribution of wind and insects to pollination. Pods from crosspollination have previously been found to have more seeds per pod than those from self-pollination (Correia et al., 2014), as expected. Correia et al. (2014) performed pollination experiments in Portugal that took into account open pollination, supplementary pollination, spontaneous autogamy, and self-pollination. But no study has yet verified the relative contribution of wind and insects to acacia seed set. On A. longifolia, insect activity is expected to be low, considering that flowering occurs at the end of winter. Honeybees have seldom been collected or recorded (Silva, 2012; Correia et al., 2014) and records lack any behavioural observation demonstrating the active involvement of the honeybee in pollen transfer at this time of the year. In fact, honeybees resuming activity after winter dormancy may be unable to keep the constancy needed for successful pollination, due to the unsuitable weather conditions. However, if we allow wind access to inflorescences, and if wind is actually able to carry and disperse pollen grains successfully, its contribution may increase cross-pollination occurrence on coastal dunes and, when compared to self-pollinated, pods should have more seeds. Similarly, insect access to inflorescences is anyway expected to increase seeds per pod, due to the well-known ability for pollen collection and transfer by bees. We planned behavioural observations, to confirm if the activity carried out on flowers was associated with pollen transfer, introducing ethological inferences on recorded pollinator activity.

\section{Materials and methods}

The study was carried out in the coastal area of Alentejo (Vila Nova de Milfontes, Portugal). The field site (Herdade dos Nascedios) is included in the protected area of Parque Natural do Sudoeste Alentejano e Costa Vicentina, a patch of natural coastal vegetation (often invaded by Acacia longifolia and Acacia saligna) and cultivated land (equally invaded on its margins). Exclusion experiments were carried out along a road on the margin of cultivated land, where $A$. longifolia was abundantly growing under Eucalyptus globulus trees. In the fields, the ongoing cultivation was that of peas, but these were not flowering at the time of observations. A honeybee survey was conducted in an adjacent area of secondary dunes that has been heavily invaded by acacias shrubs. The native plant community of the sand dunes forms an open structure with a low cover of shrubs, herbs and isolated pine trees exposed to high temperatures, high solar irradiance levels, and drought. The dominant native species includes $S$. spectabilis (Fabaceae), a sclerophyllous xerophytic $\mathrm{N}_{2}$-fixing species, morphologically characterized by small

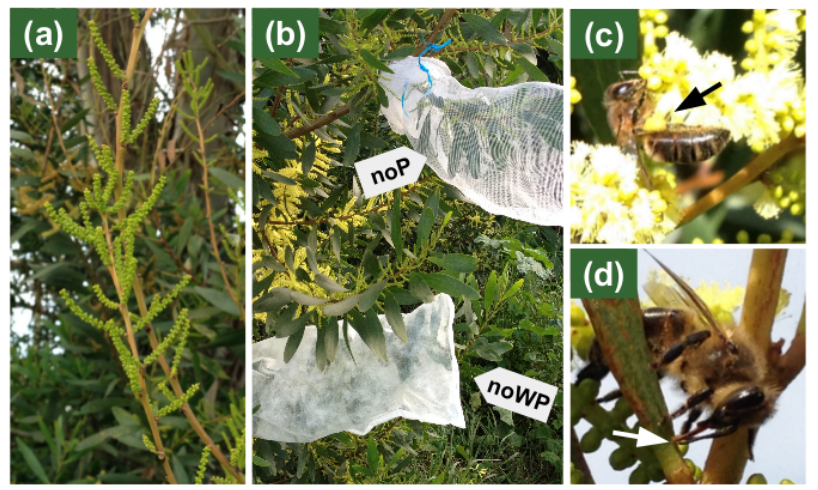

Figure 1. (a) Inflorescence at the green-button stage, as selected for the exclusion experiments; (b) mesh net positioned on the branch, of larger texture for exclusion of pollinators (noP) and allowing wind and of finer texture for exclusion of wind and pollinators (noWP); (c) Portuguese honeybee collecting pollen on A. longifolia inflorescence; black arrow indicates pollen on the corbiculae, identifying the individual as a pollen forager; (d) Portuguese honeybee collecting nectar from an extrafloral nectary (exact position indicated by the white arrow)

spiny phyllodes; C. album, a characteristic shrub species of coastal dunes, coastal cliffs, and in later successional stages on coastal habitats; several semi-deciduous typical mediterranean shrubs such as the semi-deciduous Cistus species (e.g. C. monspeliensis and C. crispus), Lavandula spp., and Rosmarinus officinalis; and other typical sand dunes species such as Helichrysum picardii, Santolina impressa, Armeria pungens, Pinus pinaster, and Thymus carnosus. Average annual temperatures range from 15.7 to $17.1^{\circ} \mathrm{C}$, while total annual precipitation is around $600 \mathrm{~mm}$.

In 2016, when data collection occurred, flowering started at the end of January, and continued till April. Not all plants of A. longifolia were at the same stage of flowering: some did not develop any inflorescence, some plants showed inflorescences at a very early stage, some plants had fully developed inflorescences at different stages, from green buttons to yellowish buds, to flowers in full anthesis. These records fit with the phenology of this species, showing a very poor synchrony in populations growing in southern Portugal (Morais and Freitas, 2015).

For the exclusion experiments, five A. longifolia plants were selected along a linear transect of about $400 \mathrm{~m}$ : plants were all showing branches with flowers at different levels of anthesis. On each plant, we selected branches with flower heads at the button stage (buttons still green; Fig. 1a), removing any flower starting to expose its stamen and anthers. Branches were chosen at short distances, to ensure similar exposure and orientation to sun and surrounding environment. Branches were randomly assigned to the following treatments: noP, denoting that pollinators' visits were excluded by applying a $2 \mathrm{~mm}$ mesh bridal veil net covering the 
entire branch (Fig. 1b); noWP, denoting that the wind and pollinators were excluded by applying a non-woven mesh net $\left(17 \mathrm{~g} \mathrm{~m}^{-2}\right.$; Fig. $\left.1 \mathrm{~b}\right)$; and $\mathrm{C}$, denoting a control without a net. Treatments were replicated three times on each of the five plants ( 45 branches in total). Nets were put in place on 1-2 February 2016, controlled every 10 days, and removed on 30 May 2016. Before putting on the net, each branch was measured for its total length, and the total number of inflorescences counted. Removal occurred by cutting the whole branch, when pods had grown but did not yet open. This way we did not lose any seed produced. Number of pods and seeds were counted in the laboratory.

Preliminary observations listed insects on inflorescences: they belonged mainly to Hymenoptera (Apidae, mostly Apis mellifera and Bombus sp.; Vespidae and Formicidae). A few Coleoptera (Scarabeidae; Curculionidae, Bruchidae) and Diptera (mainly Syrphidae) were also observed. We decided to focus on the honeybee, being more frequent and already indicated as an acacia pollinator. Honeybee survey took place along a linear transect of about $100 \mathrm{~m}$, on 30 January 2016, from 17 to 22 February 2016, and from the 17 to 24 April 2016. Each day we randomly selected from 3 to 10 plants with flowers in anthesis and checked for the presence of bees active on flower heads or phyllodes twice a day. Honeybee foraging activity is strongly related to the resource collected, pollen (Fig. 1c) or nectar (Fig. 1d). Acacia longifolia shows extrafloral nectaries (EFN) on the margin of phyllodes: nectar foragers inspect phyllodes, and may enter in contact with flower heads while moving from one phyllode to the next. When collecting pollen, pollen foragers movements are mainly among flower heads; yet, some phyllodes are visited as nectar has to be added to the pollen to pack it on the corbiculae. From 29 to 31 January 2016 we recorded the behaviour of 80 honeybee individuals on $A$. longifolia plants with fully developed inflorescences. Honeybee individuals belonged to $A$. mellifera iberiensis, smaller in size and darker in colour than other subspecies of A. mellifera (Bouga et al., 2011). Observations were performed from 09:00 to 17:00 LST, in sunny conditions. We employed focal observations, i.e. followed individual bees by sight as long as possible, recording the resource collected, the number of inspected EFN, and the number of flower heads touched by the bee body while collecting the resource (nectar on EFN or pollen). Data were normalized by total time (in hundreds of seconds) each bee was followed, and the number of inspected EFN and contacted flower heads per minute were obtained by multiplying accordingly. Finally, we randomly collected 10 individuals and with the help of a stereo-microscope we checked for the presence of polyads on different parts of the bee bodies.

Data were explored and statistically investigated with the help of SPSS (IBM, version 24). We used parametric statistics when conditions were fulfilled. Averages are reported with the standard deviation. ANOVA was performed to investigate differences among the mean of categories and groups, but when equal variances were not assumed we checked our results, applying Games-Howell post hoc tests. Nonparametric statistics (Kruskal-Wallis and Mann-Whitney tests) have been applied for data with different number of samples. The $t$ test was applied to analyse mean in two independent groups, and $\chi^{2}$ for counts.

\section{Results}

The length of the branches, chosen for exclusion experiments, varied between 21 and $73 \mathrm{~cm}$ (average: $36.97 \pm \mathrm{SE} 1.58 ; n=45)$. Accordingly, the number of flower heads varied between 23 and 91 (average: $57.31 \pm$ SE 2.21; $n=45$ ). No statistical differences emerged among categories at the level of each single plant and, similarly, variability was not significant when investigated at the level of the three categories (branches: ANOVA $\mathrm{df}=2, f=2.117, p=0.133$; flower heads: ANOVA $\mathrm{df}=2, f=0.094, p=0.111$ ). We then proceeded in analysing the results of pods and seed production combining data from all trees. Among the three categories of $\mathrm{C}$ (control), noP (no pollinators) and noWP (no wind and no pollinators), there was no statistical difference in the number of pods (Kruskal-Wallis $\chi^{2}=1.055, \mathrm{df}=2$, $p=0.590)$. The number of seeds per pod was instead significant (Kruskal-Wallis $\chi^{2}=16.936, \mathrm{df}=2, p=0.0001$; Fig. 2). The open pollination (C) produced consistently more seeds per pod than the insect exclusion treatment (noP) (Mann-Whitney $U=7, z=-2.733, p=0.006$ ). On average, $7.24 \pm$ SD 2.02 seeds (C) vs. $4.20 \pm$ SD 1.41 seeds (noP) when wind, but not pollinators, was allowed to contribute to seed set. When also wind was excluded (noWP), the average number of seeds per pod falls to $2.72 \pm \mathrm{SD} 0.78$, the difference with the open pollination (C) is even more consistent (Mann-Whitney $U=2, z=-3.628, p=0.000$ ). Most interesting, seed set from wind pollination (noP) was significantly higher than seed set from spontaneous selfpollination (noWP) (Mann-Whitney $U=13.5, z=-2.099$, $p=0.036$ ), indicating wind's contribution to seed set.

Honeybees were somehow less abundant on A. longifolia. Out of 174 surveyed plants, honeybees were recorded only on $36.21 \%$. This is statistically different from what could be expected randomly (equal chance of recording bees or not; $\left.\chi^{2}=13.241, \mathrm{df}=1 ; p=0.0003\right)$. Similar frequencies emerged when analysing data separately for February and April, confirming a non-random distribution. On a daily basis, honeybee frequency was higher in the morning $(60.3 \%)$ and lower in the afternoon $(39.7 \%)$, this trend was not deemed statistically significant $\left(\chi^{2}=2.683, \mathrm{df}=1\right.$; $p=0.102$ ).

Out of 10 honeybee individuals collected and checked for pollen grains on their body, only one did not show polyads. The remaining nine bees were carrying polyads, on an ordinal scale from rare to abundant, on different parts of their body. Pollen grains were most frequently observed on the 


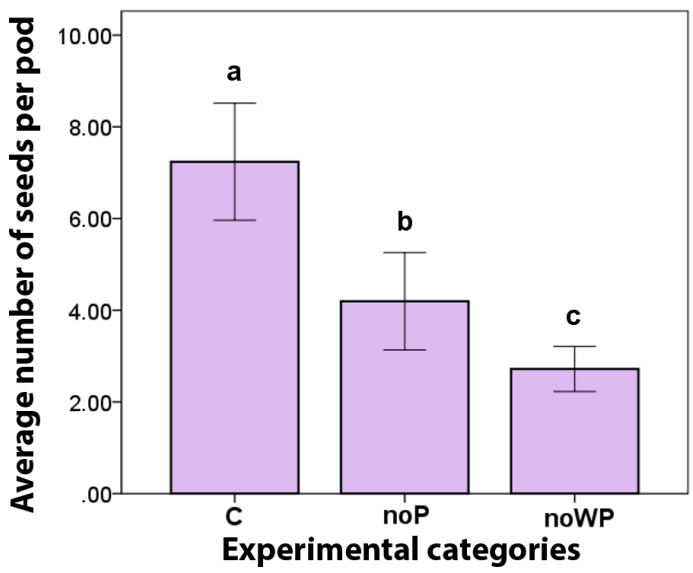

Figure 2. Average number of seed per pod, according to the experimental categories: control (C), exclusion of pollinators (noP), exclusion of wind and pollinators (noWP). Bars represent \pm SE. Letters on the top of the bars indicate significant statistical difference.

hind legs (even out of corbiculae; $90 \%$ of samples); other body parts frequently bearing pollen grains were abdomen and head (50 and $40 \%$, respectively), more rarely wings and mid-legs (30\%), and very rarely thorax and forelegs (10\%).

Activity was negatively influenced by wind, frequent especially in the afternoon: bees often lost stability and flew away instead of continuing flower visits. The average number of flower heads per minute, touched by bees foraging on flowering plants, according to the resources gathered, as well as the average number of phyllodes per minute, is reported in Table 1. Data on phyllodes sustain the division of honeybees in the two groups, nectar and pollen foragers. In fact, nectar foragers visit a significantly higher number of phyllodes per minute than pollen foragers ( $t$ test, $t=3.753$, $\mathrm{df}=78, p=0.000)$. As expected, they also contact flower heads while foraging, as do pollen foragers: there is no difference in the average number of flower heads per minute ( $t$ test, $t=-0.608, \mathrm{df}=78, p=0.545$ ) touched by foragers belonging to the two groups. Even if observations were carried out in front of plants with the majority of inflorescences fully developed, focal observations detected 14 nectar foragers and 1 pollen forager visiting EFN also on branches without inflorescences: $15.4 \%$ of all visited phyllodes. As expected, the average number of contact with flower heads decreases for nectar foragers if also considering visits to non-flowering branches $\left(7.93 \pm\right.$ SE 2.05 flower heads $\left.\mathrm{min}^{-1}\right)$.

\section{Discussion}

In acacias, less than $1 \%$ of flowers produce a seed pod and the number of seeds is also not fixed. In A. longifolia, Kenrick and Knox (1982) found up to 12 seeds per pod as a result of open pollination in Australia, while we found 10 seeds and Correia et al. (2016) found less than 6 seeds in Portugal.
Table 1. Details of honeybee survey and behavioural observations.

\begin{tabular}{|c|c|c|}
\hline \multicolumn{3}{|c|}{ Survey of honeybee presence on A. longifolia trees } \\
\hline & $\begin{array}{r}\text { Total number } \\
\text { of plants }\end{array}$ & $\begin{array}{r}\text { Percentage of } \\
\text { plants with } \\
\text { honeybees }\end{array}$ \\
\hline February (6 days) & 120 & $33.33 \%$ \\
\hline April (3 days) & 60 & $33.33 \%$ \\
\hline $\begin{array}{l}\text { All surveys pooled } \\
\text { (10 days) }\end{array}$ & 195 & $36.21 \%$ \\
\hline morning & 86 & $44.19 \%$ \\
\hline afternoon & 88 & $28.41 \%$ \\
\hline \multicolumn{3}{|c|}{ Honeybee foragers activity on A. longifolia inflorescences } \\
\hline & flower heads $\min ^{-1}$ & phyllodes $\min ^{-1}$ \\
\hline Nectar foragers & $9.13 \pm$ SD 5.20 & $6.03 \pm \mathrm{SD} 2.51$ \\
\hline Pollen foragers & $9.99 \pm \mathrm{SD} 3.51$ & $3.47 \pm$ SD 1.69 \\
\hline
\end{tabular}

Acacia is a genus that invests a lot of resources in massive flowering (Gibson et al., 2011). Acacia longifolia flowering branches are very abundant on a given plant, and number of inflorescences and flower heads and flowers are impressive (Tybirk, 1997; Fernandes et al., 2015). This fully recalls what is generally observed in anemophilous species. Regardless, when number of flowers will not be taken as a normalizing factor, the overall seed production is instead considered very high. Acacia sp. are known to produce a huge seed crop, which has been appointed as a key factor in their invasiveness ability (Kenrick, 2003). As already mentioned in the introduction, unfortunately too many gaps in the literature still exist to provide an understanding of why, on the one hand, anemophily as a syndrome reveals precise pollination mechanisms and mechanics (Ackerman, 2000), and on the other hand, there is an apparent waste of flowers when compared with the computing seed set. In our experiment, the open pollination seed set was consistently higher than that obtained excluding pollinators but allowing wind, and a statistically significant trend emerged from the exclusion of the wind. In addition, a single polyad can be accommodated in the cup-like structure of the pistil (Kenrick, 2003) thus it is potentially able to fertilize all the ovules in a single pollination event (Kendrick and Knox, 1982). Vroege and Stelleman (1990) found an as yet unpredicted contribution of wind from exclusion experiments on two species of entomophilous Salix, defining them as ambophilous. Our exclusion experiments also showed that seed set in A. longifolia is the result of mixed pollination system (i.e. ambophily), where both wind and insects play a role.

When checking for pollinators on a given plant species, we may easily incur overestimation in collecting numerical data without weighting them against an ethological approach. Previous records on A. longifolia pollinators were possibly affected in this sense. The sampling methods adopted may 
easily overestimate insects pollinating the flowers, including those simply visiting them but rarely constant in visitation rates and successful in pollen transfer. Both the report of Silva (2012) and Montesinos et al. (2016) included many visiting but not pollinating insects, as is the case of ants or the house fly. A long list of insects could then possibly be ascribed to the list of commensalists, benefiting from a (relatively new) food source to which they (mainly) rarely benefit and neither harm nor help. Bernhardt (1987) recorded the honeybee and Lasioglossum sp. as the main pollinators of acacias, but evolutionarily speaking we should be concerned about the fact that the honeybee is an alien species in Australia, and that no clear evolutionary trend towards a pollination strategy involving bees emerged in that study. Moreover, at our latitudes, the flowering boom occurs at the end of the winter, when average temperature can seldom be prohibitive for flying activity of insects. Even the strong winds are posing limits to flying ability of bees. We recorded individuals failing to collect the resource because of sudden gust of wind. The behaviour of the honeybee on A. longifolia is partly as it would be expected. The plant provides large quantities of pollen, and foragers can concentrate their visits on few flower heads to fill the pollen baskets. As each flower head is especially rich in its number of flowers and stamens, pollen foragers can probably complete their collection after visiting a relatively small number of flowers. This would justify the absence of significant differences in the number of flower heads touched by pollen and nectar foragers. The former need to pay visits to few flowers the latter come into contact with a similar number while visiting EFN. The plant provides nectar, an extra resource, even if on EFN. Honeybees learned where it is and visited numerous phyllodes. Notwithstanding the position of EFN is disconnected from the inflorescence, in many cases closeness is enough to ensure a contact between the bee body and the flowers. This was proved by focal observations of foraging bees and by data on pollen presence on nectar foragers' bodies. Usually, EFNs are mainly considered as being associated with defence carried out against ants (Grasso et al., 2015), with peaks of nectar production related to attacks by phytophagous insects (Carrillo et al., 2012). Acacia is a genus with the majority of species showing EFN (Weber and Keeler, 2012). For some of these, it has been assumed that EFN production is related to pollination as a means to enhance attraction to flowers A. longifolia is one of these species (Thorp and Sugden, 1990). We can confirm this resource to be actively sought after by honeybees, but since A. mellifera foragers are devoted daily to the collection of a single resource, the association of nectar production to flowering has yet to be disentangled. We observed nectar foragers visiting EFN on phyllodes not associated with inflorescences (elsewhere it should be discussed why these phyllodes are producing nectar), and this behaviour reduced the average number of inflorescences touched. Furthermore, honeybee frequency on plants is lower than what would be expected, as seen in the results of the study conducted by
Montesinos et al. (2016). Even if the honeybee can nowadays be considered a (frequent, good) pollinator of acacias, it may not be the evolutionarily chosen or even the most effective pollination mode. The honeybee can count on its behavioural plasticity to overcome handling inconveniences, including those associated with anemophilous species that lack a suitable landing surface (Giovanetti and Aronne, 2011). We then may expect the ubiquitous honeybee to be recorded on such inflorescences, as it was the case in the A. longifolia home range (Bernhardt, 1987), or on other acacias in invaded areas (Giovanetti et al., 2014, 2015; Giuliani et al., 2016).

Ambophilous species may enhance their pollen transfer by addressing abiotic and biotic vectors, especially when pollinator activity varies over space or time (Culley et al., 2002) and advantages have been predicted in very different environments, from alpine to tropical (Duan et al., 2009; Yamasaki and Sakai, 2013). Understanding pollination modes can then give important insight on pressing current and future environmental issues, especially as the invisibility pathways and expansion processes associated with invasive alien species discussed in this paper. However, it remains to be determined whether ambophily in Acacia represents a stable or transitional strategy. It is undoubtedly of help in invaded areas, and if wind would turn out to be seldom more important than insects, it may justify the incredible aggressiveness showed by this species in Portugal, especially on the coasts, and even allow to further discussion of evolutionary changes from entomophily to ambophily or even anemophily.

Data availability. Data are not publicly accessible in their present form, but can be shared by the authors upon request.

Competing interests. The authors declare that they have no conflict of interest.

Acknowledgements. The study benefited from the logistical support of "Sousa Prado \& Filhos". We are indebted to Miguel Prado for encouraging this research and providing help during fieldwork as well as thought provoking brainstorming. We are also indebted to Manuel João Pinto, who helped us with the description of sand dune vegetation and with two reviewers that gave us great insights. Manuela Giovanetti was sustained by a short-term scientific mission grant from the COST Action ALIEN Challenge (COST-STSM-ECOST-STSM-TD1209-250116-062066).

Edited by: Adrian Brennan

Reviewed by: James Rodger and one anonymous referee

\section{References}

Ackerman, J. D.: Abiotic pollen and pollination: ecological, functional, and evolutionary perspectives, Plant Syst. Evol., 222, 167-185, https://doi.org/10.1007/BF00984101, 2000. 
Al-Eisawi, D. and Dajani, B.: Airborne pollen of Jordan, Grana, 27, 219-227, https://doi.org/10.1080/00173138809428929, 1988.

Aronne, G., Giovanetti, M., Guarracino, M. R., and Micco, V.: Foraging rules of flower selection applied by colonies of Apis mellifera: ranking and associations of floral sources, Funct. Ecol., 26, 1186-1196, https://doi.org/10.1111/j.1365-2435.2012.02017.x, 2012.

Bernhardt, P.: A comparison of the diversity, density, and foraging behavior of bees and wasps on Australian Acacia, Ann. Missouri Bot. Gard., 74, 42-50, https://doi.org/10.2307/2399260, 1987.

Bernhardt, P., Kenrick, J., and Knox, R. B.: Pollination biology and the breeding system of Acacia retinodes (Leguminosae: Mimosoideae), Ann. Missouri Bot. Garden, 7, 17-29, 1984.

Bouga, M., Alaux, C., Bienkowska, M., Büchler, R., Carreck, N. L., Cauia, E., and Gregorc, A.: A review of methods for discrimination of honey bee populations as applied to European beekeeping, J. Apic. Res., 50, 51-84, https://doi.org/10.3896/IBRA.1.50.1.06, 2011.

Breton, C., Guerin, J., Ducatillion, C., Medail, F., Kull, C. A., and Berville, A.: Taming the wild and "wilding" the tame: tree breeding and dispersal in Australia and the Mediterranean, Plant Sci., 175, 197-205, https://doi.org/10.1016/j.plantsci.2008.05.013, 2008.

Carrillo, J., Wang, Y., Ding, J., and Siemann, E.: Induction of extrafloral nectar depends on herbivore type in invasive and native Chinese tallow seedlings, Basic Appl. Eco., 13, 449-457, https://doi.org/10.1093/aob/mct129, 2012.

Castroviejo, S. (Ed.): Flora ibérica: plantas vasculares de la Península Ibérica e Islas Baleares, 6, Rosaceae (Vol. 6), Editorial CSIC-CSIC Press, 1998.

Correia, M., Castro, F., Ferrero, V., Crisóstomo, J. A., and Rodríguez-Echeverría, S.: Reproductive biology and success of invasive Australian acacias in Portugal, Bot. J. Linnean Soc., 174, 574-588, https://doi.org/10.1111/boj.12155, 2014.

Correia, M., Montesinos, D., French, K., and Rodríguez-Echeverría, S.: Evidence for enemy release and increased seed production and size for two invasive Australian acacias, J. Ecol., 104, 13911399, 2016.

Culley, T. M., Weller, S. G., and Sakai, A. K.: The evolution of wind pollination in angiosperms, Trends Ecol. Evol., 17, 361369, https://doi.org/10.1016/S0169-5347(02)02540-5, 2002.

Del-Claro, K., Stefani, V., Lange, D., Vilela, A. A., Nahas, L., Velasques, M., and Torezan-Silingardi, H. M.: The importance of natural history studies for a better comprehension of animal-plant interaction networks, Biosci. J., 29, 439-448, 2013.

Del Vecchio, S., Acosta, A., and Stanisci, A.: The impact of Acacia saligna invasion on Italian coastal dune EC habitats, Comptes Rendus Biologies, 336, 364-369, 2013.

Duan, Y. W., Zhang, T. F., He, Y. P., and Liu, J. Q.: Insect and wind pollination of an alpine biennial Aconitum gymnandrum (Ranunculaceae), Plant Biol., 11, 796-802, https://doi.org/10.1111/j.1438-8677.2009.00195.x, 2009.

Faegri, K. and Van der Pijl, L.: The principles of pollination ecology, Pergamon Press, Oxford, 1979.

Fernandes, P., Antunes, C., Correia, O., and Máguas, C.: Do climatic and habitat conditions affect the reproductive success of an invasive tree species? An assessment of the phenology of Acacia longifolia in Portugal, Plant. Ecol., 216, 343-355, https://doi.org/10.1007/s11258-014-0441-9, 2015.
Friedman, J. and Barrett, S. C.: Wind of change: new insights on the ecology and evolution of pollination and mating in windpollinated plants, Ann. Bot., 103, 1515-1527, 2009.

Gibson, M. R., Richardson, D. M., Marchante, E., Marchante, H., Rodger, J. G., Stone, G. N., and Johnson, S. D.: Reproductive biology of Australian acacias: important mediator of invasiveness?, Divers. Distrib., 17, 911-933, https://doi.org/10.1111/j.14724642.2011.00808.x, 2011.

Giovanetti, M. and Aronne, G.: Honey bee interest in flowers with anemophilous characteristics: first notes on handling time and routine on Fraxinus ornus and Castanea sativa, Bull. Insectol., 64, 77-82. 2011

Giovanetti, M., Vuković, N., and Jelaska, S. D.: Australian acacias across eastern Adriatic-abundant but not aggressive, Period. Biol., 116, 275-283, 2014.

Giovanetti, M., Lippi, M. M., Foggi, B., and Giuliani, C.: Exploitation of the invasive Acacia pycnantha pollen and nectar resources by the native bee Apis mellifera, Ecol. Res., 30, 1065-1072, https://doi.org/10.1007/s11284-015-1308-9, 2015.

Giuliani, C., Giovanetti, M., Foggi, B., and Mariotti Lippi, M.: Two alien invasive acacias in Italy: differences and similarities in their flowering and insect visitors, Plant Biosyst., 150, 285294, https://doi.org/10.1080/11263504.2014.984792, 2016.

Goulson, D.: Foraging strategies of insects for gathering nectar and pollen, and implications for plant ecology and evolution, Perspect. Plant. Ecol., 2, 185-209, 1999.

Grasso, D. A., Pandolfi, C., Bazihizina, N., Nocentini, D., Nepi, M., and Mancuso, S.: Extrafloral-nectar-based partner manipulation in plant-ant relationships, AoB Plants, 7, 1-15, https://doi.org/10.1093/aobpla/plv002, 2015.

Guinet, P.: Mimosoideae: the characters of their pollen grains, edited by: Polhill, R. M. and Raven, P. H., Advances in legume systematics, Kew, RBG, 835-857, 1981.

Hellmann, C., Sutter, R., Rascher, K. G., Máguas, C., Correia, O., and Werner, C.: Impact of an exotic $\mathrm{N}_{2}$-fixing Acacia on composition and $\mathrm{N}$ status of a native Mediterranean community, Acta Oecol., 37, 43-50, https://doi.org/10.1016/j.actao.2010.11.005, 2011.

Hurtado, I. and Alson, J.: Aeropollen of Mimosoideae, edited by: Muilenberg, M. L. and Burge, H. A., Aerobiology, 1996.

Kenrick, J.: Review of pollen-pistil interactions and their relevance to the reproductive biology of Acacia, Aust. Syst. Bot., 16, 119130, https://doi.org/10.1080/0028825X.1972.10428619, 2003.

Kenrick, J. and Knox, R. B.: Function of the polyad in reproduction of Acacia, Ann. Bot., 50, 721-727, https://doi.org/10.1080/00087114.2012.760881, 1982.

Knox, R. B., Kenrick, J., Bernhardt, P., Marginson, R., Beresford, G., Baker, I., and Baker, H. G.: Extrafloral nectaries as adaptations for bird pollination in Acacia terminalis, Am J Bot., 72, 1185-1196, 1985.

Lazzaro, L., Giuliani, C., Fabiani, A., Agnelli, A. E., Pastorelli, R., Lagomarsino, A., and Foggi, B.: Soil and plant changing after invasion: The case of Acacia dealbata in a Mediterranean ecosystem, Sci. Total Environ., 497, 491-498, 2014.

Marchante, H., Marchante, E., and Freitas, H.: Invasion of the Portuguese dune ecosystems by the exotic species Acacia longifolia (Andrews) Willd.: effects at the community level, edited by: Child, L., Brock, J. H., Brundu, G., Prach, K., Pysĕk, P., Wade, P., 
and Williamson, M., Plant invasions: ecological threats and management solutions, Backhuys Publishers, Leiden, 75-85, 2003.

Montesinos, D., Castro, S., and Rodríguez-Echeverría, S.: Two invasive acacia species secure generalist pollinators in invaded communities, Acta Oecol., 74, 46-55, 2016.

Morais, M. C. and Freitas, H.: Phenological dynamics of the invasive plant Acacia longifolia in Portugal, Weed Res., 55, 555-564, 2015

Proctor, M., Yeo, P., and Lack, A. (Eds): The Natural History of Pollination, Timber Press, Portland, Oregon, USA, 1996.

Rascher, K. G., Große-Stoltenberg, A., Máguas, C., MeiraNeto, J. A. A., and Werner, C.: Acacia longifolia invasion impacts vegetation structure and regeneration dynamics in open dunes and pine forests, Biol. Inv., 13, 1099-1113, https://doi.org/10.1007/s10530-011-9949-2, 2011a.

Rascher, K. G., Große-Stoltenberg, A., Máguas, C., and Werner, C.: Understory invasion by Acacia longifolia alters the water balance and carbon gain of a Mediterranean pine forest, Ecosystems, 14, 904-919, 2011b.

Rascher, K. G., Hellmann, C., Máguas, C., and Werner, C.: Community scale ${ }_{15} \mathrm{~N}$ isoscapes: tracing the spatial impact of an exotic $\mathrm{N}_{2}$-fixing invader, Ecol. Lett., 15, 484-491, https://doi.org/10.1111/j.1461-0248.2012.01761.x, 2012.

Richardson, D. M., Carruthers, J., Hui, C., Impson, F. A., Miller, J. T., Robertson, M. P., and Wilson, J. R.: Humanmediated introductions of Australian acacias - a global experiment in biogeography, Divers. Distrib., 17, 771-787, https://doi.org/10.1111/j.1472-4642.2011.00824.x, 2011.

Romano, B.: Pollen monitoring in Perugia and information about aerobiological data, Aerobiologia, 4, 20-26, 1988.
Sanchez-Medina, M. S. and Fernandez, A.: Allergenic pollens in Bogotá, Colombia, South America, J. Allergy, 38, 46-50, https://doi.org/10.1016/0021-8707(66)90072-4, 1966.

Silva, P. M.: Invasão de Ecosistemas por Acacia longifolia - Caracterização da entomofauna associada e identificação de potenciais polinizadores, Master's Thesis, Faculty of Science and Tecnology, New University of Lisbon, Lisbon, 2012.

Stone, A. G. N., Raine, B. N. E., Prescott, C. M., and Willmer, D. P. G.: Pollination ecology of acacias (Fabaceae, Mimosoideae), Aust. Syst. Bot., 16, 103-118, https://doi.org/10.1071/SB02024, 2003.

Thorp, R. W. and Sugden, E. A.: Extrafloral nectaries producing rewards for pollinator attraction in Acacia longifolia (Andr.) Willd, Israel J. Bot., 39, 77-186, 1990.

Tybirk, K.: Reproductive biology and evolution of the genus Acacia, International Group for the Study of Mimosoideae, 20, 45-53, 1997.

Ulm, F., Hellmann, C., Cruz, C., and Máguas, C.: N/P imbalance as a key driver for the invasion of oligotrophic dune systems by a woody legume, Oikos, 126, 231-240, https://doi.org/10.1111/oik.03810, 2017.

Vroege, P. W. and Stelleman, P.: Insect and wind pollination in Salix repens L. and Salix caprea L., Israel J. Bot., 39, 125-132. 1990.

Weber, M. G. and Keeler, K. H.: The phylogenetic distribution of extrafloral nectaries in plants, Ann. Bot., 111, 1251-1261, https://doi.org/10.1093/aob/mcs225, 2012.

Yamasaki, E. and Sakai, S.: Wind and insect pollination (ambophily) of Mallotus spp.(Euphorbiaceae) in tropical and temperate forests, Aust. J. Bot., 61, 60-66, https://doi.org/10.1071/BT12202, 2013. 